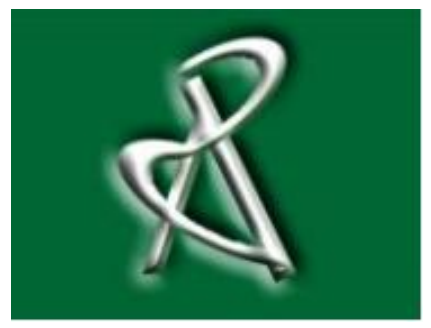

Available online at www.academicpaper.org

\section{Academic@ @aper}

ISSN 2146-9067

International Journal of Automotive Engineering and Technologies

Vol. 5, Issue 1, pp. $17-24,2016$

\section{Original Research Article}

International Journal of Automotive

Engineering and Technologies

http://www.academicpaper.org index.php/IJAET

\title{
Mathematical Model for Fuel Flow Performance of Diesel Engine
}

\author{
Adnan Berber*
}

Department of Mechanical Engineering, Seydişehir Faculty of Engineering N.E. University, Konya/Turkey

Received 26 February 2016 Accepted 06 March 2016

\begin{abstract}
In this paper, response surface method (RSM) was proposed to determine fuel flow performance of an internal combustion diesel engine by using different specific conditions (injection pressure, engine speed and throttle position). Injection pressure of the diesel engine was chosen as 150 bars for turbocharger and pre-combustion chamber. Experiments were realized at four pressures corresponding to 100,150 , 200 and 250 bars each with throttle positions of 50, 75 and 100\%. A mathematical model was used to predict fuel flow performance of engine according to pressures and throttle positions. The optimum performance conditions, for a required fuel flow, were obtained by using response surface method with 3D graphics. The developed prediction equations showed that the linear effect of engine speeds was the most important factor that influenced the fuel flow. Moreover, whether the proposed mathematical model of fuel flow is within the limits of the performance parameters has been considered.
\end{abstract}

Keywords: Diesel engine performance, fuel flow, mathematical modeling, response surface method.

doi: 10.18245/ijaet.56033

*Corresponding Author:

Tel. : :90505 5115277

E-mail : aberber@konya.edu.tr 


\section{Introduction}

Many experimental investigations about biodiesel production and its combustion emission have been realized. Aktaş et al [1] investigated biodiesel production from olive pulp in their research and also Behçet R. [2] researched biodiesel production from waste fish oils and its harmful effects on the environment and human health. Aktaş A. examined that mixture of melon seed oil and methyl esters with diesel fuel and its effects on engine performance and emissions [3]. As such, many researchers produced different biodiesel fuel and investigated the effects of these fuels on engine performance [4-9].

Analytical methods, numerical methods or experimental measurement methods have been used to solve internal combustion engine problems. Formerly, the limitations of computer speed and storage made analytical methods more favorable to examine many problems. However, experimental measurement methods have been preferred when analytical methods were impossible in some situations Çelikten et al [10].Therefore especially after

1990s, researchers developed numerical methods for accurate and efficient solutions. Recently, there is a trend toward optimization techniques that is done realized by using the results of experimental studies. The optimization techniques as simplex method, response surface method, artificial neural network (ANN) have been used for engine analysis [11-13]. Neşeli et al. [14] investigated influence of tool geometry on the surface finish obtained in turning of AISI 1040 steel. In order to find out the effect of tool geometry parameters on the surface roughness during turning, response surface methodology (RSM) has been used and a prediction model has been developed related to average surface roughness ( $\mathrm{Ra}$ ) using experimental data. Many similar studies about machinery manufacturing techniques were realized by experimentally and the results of experiments were used for RSM modeling. However, in our knowledge, there are no studies in literature related with RSM modeling of internal combustion diesel engine. Some researchers used experimental data to create RSM for mathematical model and they defined engine performance parameters such as power output, brake specific fuel consumption, fuel conversion efficiency, fuel injection timing, engine load, simulate altitude and oxygen volume fraction [15-16].

In this study, the fluid flow performance values for a diesel engine using response surface method (RMS) have been investigated. For this aim, experiments have been performed for both full and partial loads on a turbocharger diesel-engine with fourcylinder, four-stroke, indirect injection by changing the injection pressures from 100 to 250 bar with intervals of 50 bar and for throttle positions of 50, 75 and $100 \%$. The developed prediction equations showed that the linear effect of engine speeds was the most important factor that influenced the fuel flow.

\section{Experimental Set up and Measurements}

Nowadays, fuel injection systems and injection pressure can be successfully adjusted in high pressure. This process increases the efficiency of diesel engine. Injection characteristics of diesel engine with direct injection have been studied in several researches. For instance in Ref Yang et al. [17] parameters have been calculated according to rotation and injection pressure. Employing some mathematical models to estimate engine emissions is another approach. But high accuracy of these approaches may not be ensured Massie [18]. An alternative to mathematical models can be experiment-based approaches. However, although reliable results can be obtained, experimental studies conducted to measure emission and performance of diesel engines are complicated, time consuming and expensive.

Specifications of the test engine are given in Table 1 [19-20]. Here, the specification of our test environment (i.e. the diesel engine) and the accuracy of the equipment used to collect the necessary data are summarized. In this study, an electrical dynamometer assembled on 4cylinder and 4-stroke indirect injection diesel 
engine was used. As shown in Fig. 1, there are different thermocouples and electrical units on the dynamometer and the engine.

Table 1. Specifications of the test engine.

\begin{tabular}{|c|c|}
\hline Item & Specifications \\
\hline Make and model & $18 \mathrm{~T}, 1998$ \\
\hline Motor type & $\begin{array}{l}\text { Turbocharged, diesel, } \\
\text { pre-combustion } \\
\text { chamber, four-stroke }\end{array}$ \\
\hline $\begin{array}{l}\text { Number of cylinders } \\
\text { and volume }\end{array}$ & Four-cylinders and 1.81 \\
\hline $\begin{array}{l}\text { Engine power and } \\
\text { torque }\end{array}$ & $\begin{array}{l}44 \mathrm{~kW} \text { at } 4800 \mathrm{rpm}, 110 \\
\mathrm{Nm} \text { at } 2500 \mathrm{rpm}\end{array}$ \\
\hline $\begin{array}{l}\text { Fuel system and } \\
\text { injectors }\end{array}$ & $\begin{array}{l}\text { Lucas DPC type fuel- } \\
\text { injection pump, single- } \\
\text { point fuel injectors }\end{array}$ \\
\hline
\end{tabular}

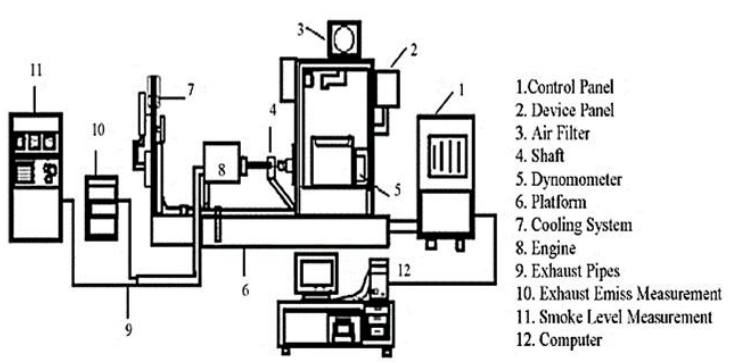

Fig. 1. Schematic picture of engine test bed.

Circuits in all units have been connected to each other, and they have also been controlled by a computer. In addition, there are two exhaust emission measurement equipment worked separately. One of the equipment was used for fuel flow measurements, and the other for other engine performance level. After nozzles that are changed pressure adjustment are assembled, they are investigated according to engine performance and emission for different throttle positions. Experiments have been conducted on a diesel engine connected with an electrical dynamometer. Before starting the engine, the nozzles were taken off and adjusted to 150 bars. For the adjustment, washer(s) has been used to change the nozzles pressures. After that, the nozzles adjusted have been fitted to the engine. Then, air in the nozzles has been transferred to the atmosphere and the engine was run. The computer controlled diesel engine which is connected to the electrical dynamometer was loaded in throttle position of $50 \%$. Engine was tested in range of $1500 \mathrm{rpm}$ to $4500 \mathrm{rpm}$ with the interval of $500 \mathrm{rpm}$. In the throttle position, maximum torque level of $4500 \mathrm{rpm}$ was reached. In the experiments, torque, power and fuel flow rate were recorded by computer. Similarly, these measurements were repeated in throttle positions of $75 \%$ and $100 \%$. Fuel-air equivalence ratios are measured in the experiments, as well.

\section{Material and Methods}

Response Surface Methodology or (RSM) is a collection of mathematical and statistical techniques useful for the modeling and analysis of problems in which a response of interest is influenced by several variables and the objective is to optimize this response Montgomery [21]. For example, operation of a diesel internal combustion engine is effected by rpm and amount of the fuel flow. Engine work condition can be any combination of $x_{1}$ and $x_{2}$. Therefore, $x_{1}$ and $\mathrm{x}_{2}$ can vary continuously. When treatments are from a continuous range of values, then an RSM is useful for developing, improving, and optimizing the response variable. In this case, $\mathrm{y}$ is the response variable, and it is a function of rpm and Ip. It can be expressed as follows:

$\mathrm{y}=\mathrm{f}\left(\mathrm{x}_{1}, \mathrm{x}_{2}\right)+\varepsilon$

The variables $\mathrm{x}_{1}$ and $\mathrm{x}_{2}$ are independent variables where the response $y$ depends on them. The dependent variable $y$ is a function of $\mathrm{x}_{1}, \mathrm{x}_{2}$, and the experimental error term, denoted as $\varepsilon$. The error term $\varepsilon$ represents any measurement error on the response, as well as other type of variations not counted in $\mathrm{f}$. It is a statistical error that is assumed to distribute normally with zero mean and variance $\mathrm{s}_{2}$. In most RSM problems, the true response function $f$ is unknown. In order to develop a proper approximation for $f$, the experimenter usually starts with a low-order polynomial in some small region. If the response can be defined by a linear function of independent variables, then the approximating function is a first-order model. A first-order model with 2 independent variables can be expressed as: $y=\beta_{0}+\beta_{1} x_{1}+\beta_{2} x_{2}+\varepsilon$

If there is a curvature in the response surface, then a higher degree polynomial should be used. The approximating function with 2 variables is 
called a second-order model:

$y=\beta_{0}+\beta_{1} x_{1}+\beta_{2} x_{2}+\beta_{11} x^{2}{ }_{11}+\beta_{22} x^{2}{ }_{22}+\beta_{12}$ $\mathrm{x}_{1} \mathrm{x}_{2}+\varepsilon$

In general, all RSM problems use either one or the mixture of the both of these models. In each model, the levels of each factor are independent of the levels of other factors. In order to get the most efficient result in the approximation of polynomials the proper experimental design must be used to collect data. Once the data are collected, the Method of Least Square is used to estimate the parameters in the polynomials. The response surface analysis is performed by using the fitted surface. The response surface designs are types of designs for fitting response surface. Therefore, the objective of studying RSM can be accomplish by (1) understanding the topography of the response surface (local maximum, local minimum, ridge lines), and (2) finding the region where the optimal response occurs. The goal is to move rapidly and efficiently along a path to get to a maximum or a minimum response so that the response is optimized. The RSM is important in designing, formulating, developing, and analyzing new scientific studying and products. It is also efficient in the improvement of existing studies and products. The most common applications of $R S M$ are in Industrial, Biological and Clinical Science, Social Science, Food Science, and Physical and Engineering Sciences. Since $R S M$ has an extensive application in the realworld, it is also important to know how and where Response Surface Methodology started in the history. According to Hill and Hunter, $R S M$ method was introduced by G.E. P. Box and K.B. Wilson in 1951 (Wikipedia 2006). Box and Wilson suggested to use a first-degree polynomial model to approximate the response variable. They acknowledged that this model is only an approximation, not accurate, but such a model is easy to estimate and apply, even when little is known about the process (Wikipedia 2006). Moreover, Mead and Pike stated origin of RSM starts 1930s with use of Response Curves (Myers, Khuri, and Carter 1989).According to research conducted
(Myers, Khuri, and Carter 1989), the orthogonal design was motivated by Box and Wilson (1951) in the case of the first-order model. For the second-order models, many subject- matter scientists and engineers have a working knowledge of the central composite designs (CCDs) and three-level designs by Box and Behnken (1960). Also, the same research states that another important contribution came from Hartley (1959), who made an effort to create a more economical or small composite design. There exist many papers in the literatures about the response surface models. In contrast, 3-level fractional design has limited works. Thus, 3level fractional design is an open research subject. Fractional Factorial Experiment Design for Factor at 3-Levels (Connor and Zelen 1959) is a helpful resource conducting this kind of design. Many three- level fractional factorial designs and more importantly their alias tables can be found in their study. According to (Myers, Khuri, and Carter 1989), the important development of optimal design theory in the field of experimental design emerged following Word World II. Elfving (1952, 1955, 1959), Chernoff (1953), Kiefer (1958, 1959, 1960, 1962), and Kiefer and Wolfowitz were some of the various authors who published their work on optimality. One of the important facts is whether the system contains a maximum or a minimum or a saddle point, which has a wide interest in industry. Therefore, RSM is being increasingly used in the industry. Also, in recent years more emphasis has been placed by the chemical and processing field for finding regions where there is an improvement in response instead of finding the optimum response (Myers, Khuri, and Carter 1989). As a result, application and development of RSM will continue to be used in many areas in the future Bradley [22].

\section{Response Equation for Fluid Flow}

RSM's Box-Behnken design consisting of 84 experiments was conducted for developing the mathematical model for fuel flow attained by the experimental set up. The input 
parameters and their levels chosen for this work are given in Table 1. The fluid flow results for the 17 experiments are given in Table 2.

Table 2. Input parameters and their levels.

\begin{tabular}{llll}
\hline SN & Parameter & Low Level & High Level \\
\hline 1 & $\begin{array}{l}\text { Throttle } \\
\text { position (\%) }\end{array}$ & 50 & 95 \\
2 & $\begin{array}{l}\text { Injection } \\
\text { pressure } \\
\text { (Bar) }\end{array}$ & 100 & 250 \\
3 & $\begin{array}{l}\text { Engine } \\
\text { speed(rpm) }\end{array}$ & 1500 & 4500 \\
4 & $\begin{array}{l}\text { Fuel flow } \\
(\mathrm{kg} / \mathrm{hr})\end{array}$ & 4.7 & 15.9 \\
\hline
\end{tabular}

\section{Result and Discussions}

The analysis of variance (ANOVA) was applied to study the effect of the input parameters on the fuel flow. Table 3 gives the model summary statistics. It reveals that quadratic model is the best suggested model. So, for further analysis this model was used.

Table 3. Model summary statistics.

\begin{tabular}{lll}
\hline Source & $\mathrm{R}^{2}$ & Adj $\mathrm{R}^{2}$ \\
\hline Linear & 0.72 & 0.72 \\
Square & 0.86 & 0.84 \\
Interaction & 0.93 & 0.93 \\
\hline
\end{tabular}

The value of "Prob. > $F$ " in Table 4 for model is less than 0.05 which indicates that the model is significant, which is desirable as it indicates that the terms in the model have a significant effect on the response. In the same manner, the two-level interaction of injection pressure-engine speed (Ip $\mathrm{x}$ rpm) and injection pressure-throttle position are not significant model terms. Other model terms can be said to be significant. These insignificant model terms (not counting those required to support hierarchy) can be removed and may result in an improved model.

Estimated regression coefficients for surface roughness using data are shown in Table 5. The co-efficient of determination $\mathrm{R}^{2}$ is used to decide whether a regression model is appropriate. The co-efficient of determination $\mathrm{R}^{2}$ provides an exact match if it is 1 . So, the quadratic model of response equation in terms of actual factors for fuel flow (Ff) is;

$\mathrm{Ff}=-13.2390+0.0463 \mathrm{Ip}-0.0001 \mathrm{Ip}^{2}+0.0001 \mathrm{rpm}-$ $0.0000 \mathrm{rpm}^{2}+0.3972 \mathrm{Tp}-90034 \mathrm{Tp}^{2}+0.0000 \mathrm{Ip} \mathrm{rpm}-0.0002 \mathrm{Ip}$ $\mathrm{Tp}+0.0001 \mathrm{rpm} \mathrm{Tp}$

Table 4. ANOVA table for response surface model.

\begin{tabular}{cccccccc}
\hline & SS & df & MS & F & Prob.>F & PC(\%) & $\mathrm{R}^{2}(\%)$ \\
\hline Ip & 30.004 & 1 & 30.0037 & 32.7248 & 0.000000 & 2.59 & \\
Ip $^{2}$ & 10.497 & 1 & 10.4967 & 11.4487 & 0.001147 & 1.02 & \\
rpm & 493.834 & 1 & 493.8338 & 538.6207 & 0.000000 & 48.17 & \\
rpm $^{2}$ & 14.545 & 1 & 14.5453 & 15.8644 & 0.000158 & 1.41 & \\
Tp & 174.512 & 1 & 174.5118 & 190.3386 & 0.000000 & 17.02 & \\
Tp & 55.108 & 1 & 55.1083 & 60.1061 & 0.000000 & 5.37 & 93.38 \\
IpxRPM & 0.433 & 1 & 0.4335 & 0.4728 & 0.493850 & 0.00 & \\
IpxTp & 2.194 & 1 & 2.1935 & 2.3925 & 0.126188 & 0.00 & \\
rxTp & 136.877 & 1 & 136.8768 & 149.2905 & 0.000000 & 13.35 & \\
Error & 67.847 & 74 & 0.9168 & & & & \\
Total SS & 1025.059 & 83 & & & & & \\
\hline
\end{tabular}

The empirical Eq. (4) shows greater agreement than $93 \%$ in the fit values. The $\mathrm{R}^{2}$ value in this case is high and close to 1 , which is desirable. Hence, these equations can be used for determining the fuel flow in diesel engine. The normal probability plot of the observed versus the predicted response for surface roughness is shown in Fig. 2. A check on the plot in Fig. 2 revealed that the observed generally fall on a straight line implying that the errors are distributed normally. This implies that the models proposed are adequate and there is no reason to suspect any violation of the independence or constant variance assumption. The effect of throttle position (Tp), engine speed (rpm) 
and injection pressure (Ip) on fuel flow is shown in Fig. 3 via 3D surface graphs. Fig. 3 a clearly displays that the value of fuel flow (Ff) increases with increase in the effect of throttle position (Tp) and engine speed (rpm). This result is compatible with the general expectation. Increasing rpm and decreasing Ip (Fig. 3b) have caused an increase in Ff. Like the situation in (Fig 3b), increasing Tp and decreasing Ip (Fig. 3c) have caused to reach to maximum values of $\mathrm{Ff}$.

Table 5. Estimated regression coefficients for Ff.

\begin{tabular}{|c|c|c|c|c|c|}
\hline & $\begin{array}{c}\text { Regress } \\
\text { ion }\end{array}$ & $\begin{array}{l}\text { Std. } \\
\text { Err. }\end{array}$ & $\mathrm{t}$ & $\mathrm{p}$ & $\begin{array}{l}\mathrm{R}^{2} \\
(\%) \\
\end{array}$ \\
\hline $\begin{array}{c}\text { Mean/Int } \\
\text { erc. }\end{array}$ & $\begin{array}{c}- \\
13.239 \\
0\end{array}$ & $\begin{array}{c}3.393 \\
137\end{array}$ & $\begin{array}{c}- \\
3.901 \\
69\end{array}$ & $\begin{array}{c}0.000 \\
209\end{array}$ & \multirow{10}{*}{$\begin{array}{l}93 . \\
38\end{array}$} \\
\hline Ip & 0.0463 & $\begin{array}{c}0.017 \\
444\end{array}$ & $\begin{array}{c}2.655 \\
22\end{array}$ & $\begin{array}{c}0.009 \\
700\end{array}$ & \\
\hline $\mathrm{Ip}^{2}$ & -0.0001 & $\begin{array}{c}0.000 \\
042\end{array}$ & $\begin{array}{c}- \\
3.383 \\
59\end{array}$ & $\begin{array}{c}0.001 \\
147\end{array}$ & \\
\hline rpm & 0.0001 & $\begin{array}{c}0.000 \\
903\end{array}$ & $\begin{array}{c}0.064 \\
18\end{array}$ & $\begin{array}{c}0.948 \\
999\end{array}$ & \\
\hline $\mathrm{rpm}^{2}$ & -0.0000 & $\begin{array}{c}0.000 \\
000\end{array}$ & $\begin{array}{c}3.983 \\
02\end{array}$ & $\begin{array}{c}0.000 \\
158\end{array}$ & \\
\hline $\mathrm{Tp}$ & 0.3972 & $\begin{array}{c}0.068 \\
838\end{array}$ & $\begin{array}{c}5.770 \\
28\end{array}$ & $\begin{array}{c}0.000 \\
000\end{array}$ & \\
\hline $\mathrm{Tp}^{2}$ & -0.0034 & $\begin{array}{c}0.000 \\
444\end{array}$ & $\begin{array}{c}- \\
7.752 \\
82\end{array}$ & $\begin{array}{c}0.000 \\
000\end{array}$ & \\
\hline Ipxrpm & 0.0000 & $\begin{array}{c}0.000 \\
002\end{array}$ & $\begin{array}{c}0.687 \\
61\end{array}$ & $\begin{array}{c}0.493 \\
850\end{array}$ & \\
\hline IpxTp & -0.0002 & $\begin{array}{c}0.000 \\
102\end{array}$ & $\begin{array}{c}1.546 \\
76\end{array}$ & $\begin{array}{c}0.126 \\
188\end{array}$ & \\
\hline $\mathrm{rpm} \times \mathrm{xp}$ & 0.0001 & $\begin{array}{c}0.000 \\
006\end{array}$ & $\begin{array}{c}12.21 \\
845\end{array}$ & $\begin{array}{c}0.000 \\
000\end{array}$ & \\
\hline
\end{tabular}

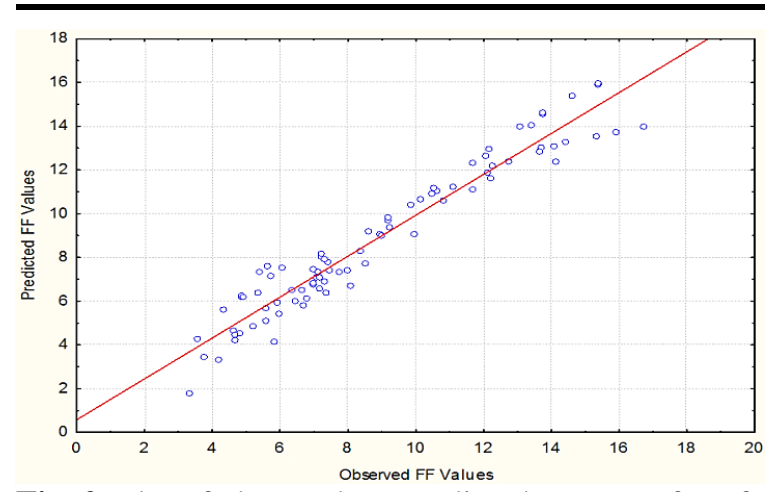

Fig. 2. Plot of observed vs. predicted response for Ff.

\section{Conclusions}

The aim of this paper is to show the possibility of using the RSM for fuel flow performance prediction of a diesel engine employing the experimental data. The experimental results of an internal combustion diesel engine are used to estimate the fuel flow performance by using RSM modeling. Relations between the parameters such as the fuel flow, the engine speed, the injection pressure and the throttle positions are found using RSM. The RSM approach based modeling analysis has been carried out for optimizing the performance of diesel engine. It is found that the most important parameter affecting the fuel flow is engine speed. The results of RSM of four-stroke IC diesel engine are observed to be very close with the experimental results. It is obtained that the $\mathrm{R}^{2}$ value is 93.38 . This study was also conducted to fill a gap in the literature in this subject.

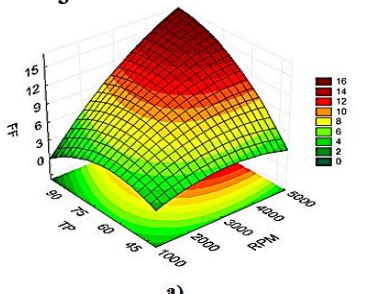

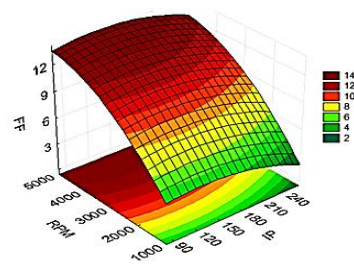

b)

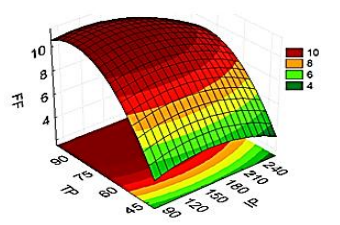

Fig. 3. 3D response surface graphs for the fuel flow vs. throttle position, injection pressure and engine speed.

\section{References}

[1]Abdurrezzak Aktas, Salih Ozer, Biodiesel production from leftover olive cake Energy Education Science and Technology Part A: Energy Science and Research 2012 Volume (issues) 30 (1):8996.

[2]R. Behcet Comparison of exhaust emissions of biodiesel-diesel fuel blends produced from waste oils in Turkey Energy Education Science and Technology Part A: Energy Science and Research 1103-1114 Volume (Issue) 29 (2) July 2012.

[3]A. Aktas Effects of using blends of melon kernel oil methyl ester and Diesel fuel on the engine performance and emissions Energy Education Science and 
Technology Part A: Energy Science and Research 1183-1192.

[4]B. Gokalp, H. S. Soyhan Performance of a direct diesel engine using aviation fuels blended with biodiesel Energy Education Science and Technology Part A: Energy Science and Research 463-474 3/9Volume (Issue) 29 (1) April 2012.

[5]Singh, D. Pant, S. I. Olsen, P. S. Nigam Key issues to consider in microalgae based biodiesel production Energy Education Science and Technology Part A: Energy Science and Research 687-700 Volume (Issue) 29 (1) April 2012.

[6]H. T. Akcay, S. Karslioglu Optimization process for biodiesel production from some Turkish vegetable oils and determination fuel properties Energy Education Science and Technology Part A: Energy Science and Research Volume (Issue) 28 (2) 861-868 January 2012.

[7]M. Ozcanli, A. Keskin, H. Serin, S. Yamacli, D. Ustun Effects of soybean biodiesel on engine vibration and noise emission Energy Education Science and Technology Part A: Energy Science and Research Volume (Issue) 28 (2) January 2012 949-956.

[8]Hasimoglu Performance and emission investigation of a biodiesel fueled low heat rejection diesel engine. Energy Education Science and Technology Part A: Energy Science and Research Volume (Issue) 28 (2) 1027-1038 January 2012.

[9]Ozdalyan The effect using n-butanoldiesel fuel blends at different injection pressureson the performance and emissions of diesel engines 1001-1110 Energy Education Science and Technology Part A: Energy Science and Research Volume (Issue) 28 (2) January 2012.

[10] Çelikten İ, Koca A, Arslan MA (2010). Comparison of performance and emissions of diesel fuel, rapeseed and soybean oil methyl esters injected at different pressures Renewable Energy, 35; 4: 814-820

[11] Mukherjee I, Ray K ( 2006). A review of optimization techniques in metal cutting processes. Comput Indus Eng 8; 50:15-34.

[12] Satake K, Monaka T, Yamada S, Endo H, Yamagisawa M, Abe T(2008). The rapid development of diesel engine using an optimization of the fuel injection control. Mitsubishi Heavy Industries Limited. Tech Rev 45:6-10.

[13] Alonso JM, Alvarruiz F, Desantes JM, Hernandez L, Hernandez V, Molto G (2007). Combining neural networks and genetic algorithms to predict and reduce diesel engine emission. IEEE Trans Evol Comput 11:46-55.

[14] Neşeli S, Yaldız S, Erol Türkeş E (2010). Optimization of tool geometry parameters for turning operations based on the response surface methodology Original Research Article Measurement, In Press, Accepted Manuscript, Available online 6 December.

[15] Xingzhong Y, Jia L, Guangming Z, Jingang S, Jingyi T, Guohe H (2008). Optimization of conversion of waste rapeseed oil with high FFA to biodiesel using response surface methodology Renewable Energy 33:1678-1684.

[16] Perez PL, Boehman AL (2010). Performance of a single-cylinder diesel engine using oxygen-enriched intake air at simulated high-altitude conditions Aerospace Science and Technology 14:83-94.

[17] Yang HC, Ryou HS, Jeong YT, Choi YK(1996). Spray characteristics in a direct-injection diesel engine, Atomization and Sprays 6:95-109.

[18] Massie DD (2001). Neural-network fundamentals for scientists and engineers. ECOS'01, 4-6 July, Istanbul, Turkey, 123.

[19] Berber A, Gültekin SS, Kulaksız AA, Çelikten İ (2006). Investigation Of Breake Mean Effective Pressure and Fuel Flow Performances of Diesel Engine By Using Artificial Neural Networks. Proceeding of the International Conference on modeling and simulation 2006, 28-30 august, Konya, TURKEY, 2: 577-581. 
[20] Berber A, Gültekin SS, Kulaksız AA (2010). Investigation of Break Mean Effective Pressure and Spesific Fuel Consumption Performances of Diesel Engine By Using Artificial Neural Networks The Fifth International Ege Energy Symposium and Exhibition (IEESE-5) Pamukkale Universty Denizli Turkey June 27-30.

[21] Montgomery DC, (2005). Design and Analysis of Experiments: Response surface method and designs. P. 405. New Jersey: John Wiley and Sons, Inc.

[22] Bradley N (2007). The Response Surface Methodology, Department of Mathematical Sciences Indiana University of South Bend Master of science in Applied Mathematics \& Computer Science. 